\title{
Ischemic stroke: Observations and analysis of stroke patients admitted in a tertiary hospital of Kathmandu
}

Shakya D', Shrestha $R^{2}$, Dhungana $K^{3}$, Kafle $R^{4}$, Bhatta $S^{4}$

${ }^{1}$ Dipesh Shakya, Lecturer; ${ }^{2}$ Rabindra Shrestha, Professor and Head; ${ }^{3}$ Krishna Dhungana, Associate Professor; ${ }^{4}$ Raisha Kafle, ${ }^{4}$ Sabnam Bhatta, Medical Officer; Department of Neurology, Kathmandu Medical College Teaching Hospital, Kathmandu, Nepal.

\begin{abstract}
Background: Stroke is a disabling condition that has physical and mental impact on a patient's life. Stroke is an important morbidity for low and middle income countries like Nepal. Hypertension, diabetes, smoking, and dyslipidemia are common risk factors in this regard and are inadequately controlled; mainly because of poor public awareness, inadequate infrastructure, lack of service and qualified manpower.

Objectives: This study aims to provide insight into the epidemiology and risk factors in ischemic stroke patients.

Methodology: A descriptive cross sectional study was conducted in 92 ischemic stroke patients at a tertiary care hospital Kathmandu Medical College and Teaching Hospital (KMCTH), Sinamangal, Nepal from December 2017 to June 2018. Consecutive sampling technique was used and data was collected from ischemic stroke patients above 14 years of age who were admitted in the Department of Neurology. Information regarding pre-morbid and morbid conditions, imaging findings as well as results was obtained from biochemical analysis of blood after taking consent from the patient or patient's relative. Statistical Package for the Social Sciences Version 20 was used as a tool for statistical analysis.

Results: Their mean age was 63.25 years with standard deviation of 16.45 . Dyslipidemia was the most commonly found risk factor which was present in $77.2 \%$ of the subjects, followed by smoking (59.8\%), presence of carotid artery atherosclerosis $(59.8 \%)$, hypertension $(50 \%)$, atrial fibrillation $(26.1 \%$ ) and diabetes mellitus(15.2\%). Smoking was significant in males and heart disease was mostly seen in females.

Conclusion: Dyslipidemia and smoking were the most common risk factors followed by carotid artery atherosclerosis. Patients with hypertension and dyslipidemia had higher incidence of stroke in both young and elderly group.
\end{abstract}

Key words: Atherosclerosis; Dyslipidemia; Hypertension; Risk factors; Smoking; Stroke.

DOI: https://doi.org/10.3126/jkmc.v8i2.28166

\section{INTRODUCTION}

troke is a global health problem. It is the leading $\checkmark$ cause of disability and the second leading cause of mortality worldwide' ${ }^{1}$. Hence its prevention remains the utmost importance to its management. Epidemiological studies have focused on identification of risk factors for stroke in past; the most common ones being elevated systolic blood pressure, elevated serum cholesterol level, glucose intolerance, cigarette smoking and left ventricular hypertrophy $(\mathrm{LVH})$ etc $\mathrm{C}^{2}$. Stroke, an important morbidity in the context of Sustainable Development

Address for correspondence

Dr. Dipesh Shakya

Lecturer, Department of Neurology

Kathmandu Medical College Teaching Hospital

Kathmandu, Nepal

E-mail: shakyadeepu20@hotmail.com
Goals (SDGs), is also the leading cause of disability in the Asian population ${ }^{3}$. Low and middle income countries have a higher burden and mortality due to stroke and it is increasing over time $e^{4,5}$.

According to World Health Organisation (WHO) estimates, cerebrovascular diseases accounted for 107.5 per 100,000 deaths in Nepal (age-standardized death rate) from cerebrovascular diseases in 2002 with a total Disability-Adjusted Life Years (DALY) rate of $543 / 100,000^{6}$.

According to data from World Population Prospects: the 2017 Revision, the number of older persons those aged 60 years or over is expected to more than double by 2050 and to more than triple by 2100, rising from 962 million globally in 2017 to 2.1 billion in 2050 and 3.1 
billion in 2100 . Globally, population aged 60 or over is growing faster than all younger age groups ${ }^{7}$. This is to be considered in our context as the mean age reported in stroke cases is 61 years and $61.7 \pm 14.9$ years in Nepalese studies $^{8,9}$.

A few hospital based studies have described the risk factors associated with stroke. A hospital based study reported increased percentage of smoking (58.3\%), hypertension (47.2\%), alcohol consumption (41.4\%), atrial fibrillation (12.5\%) and type 2 diabetes mellitus $(11.1 \%)$ rates in stroke patients 9 . Similarly high rates of smoking $(40.66 \%)$ and hypertension (40\%) were reported in stroke cases in a one-year hospital based study, and even higher rates of smoking (61.0\%) and hypertension $(60 \%)$ were reported in a two-year hospital based study among the stroke patients $s^{8,10}$. Thus, smoking may be considered an important modifiable risk factor for stroke than hypertension in Nepal, although optimum control of hypertension is also crucial.

Burden of stroke is growing in large parts of Asia with the growing age, rapid development, and changing life style and culture. The study will help us provide critical aspects of stoke patients in Nepal and also aids to make a designed stroke scoring tool for the population with the help of the risk factors identified by the study. Stratifying population into high, intermediate and low risk group may help health service provider to prevent stroke and finally decreasing it morbidity and mortality Also since there are only few prospective study done in stroke in Nepal till date, this study will help us give a bird eye view on the burden of the disease and its risk factors with its demographic variability.

\section{METHODOLOGY}

This descriptive cross-sectional study was carried out at Kathmandu Medical College Teaching Hospital (KMCTH), a tertiary care hospital, Sinamangal from December 2017 to June 2018. The study included patients (>14 years) with acute neurological deficit, consistent with clinical diagnosis of ischemic stroke and supported by neuroimaging (computerized tomography [CT]). All the patients were evaluated by a trained neurologist to confirm the diagnosis. Ethical clearance was received from the Institutional Review Committee of KMCTH. A written informed consent was taken either from the patient or their surrogate. Consecutive sampling technique was used. Ninety two ischemic stroke diagnosed patients admitted in the Department of Neurology of KMCTH during the study period were included. The patients were subjected to: history taking and clinical examination. Additionally, a questionnaire was used to obtain information on the pre-morbid and morbid conditions. Similarly, information from imaging such as $\mathrm{CT}$, echocardiography (ECHO), carotid doppler ultrasound, electrocardiography (ECG) as well as different biochemical parameters assessed using blood samples were collected.

The study assessed many disease conditions as risk factors. Hence, there are different operational definitions utilized in the study. A diagnosis of hypertension was made if the patient's systolic and diastolic blood pressure surpassed 140 and/or 90 millimeters of mercury respectively on repeated measurements during hospitalization or physical evaluation, or if the patient was being treated with antihypertensive drugs at the time of admission. A diagnosis of diabetes mellitus was based on self-reporting of the disease, or an observed fasting serum glucose level of $126 \mathrm{mg} / \mathrm{dL}$ or more, or if the patient was being treated with insulin or hypoglycemic drugs $^{13}$. Dyslipidemia was defined as fasting serum total cholesterol of $200 \mathrm{mg} / \mathrm{dL}$ or more, a serum lowdensity lipoprotein (LDL) of $100 \mathrm{mg} / \mathrm{dL}$ or more, and/ or a serum high-density lipoprotein (HDL) of $40 \mathrm{mg} / \mathrm{dL}$ or lower. History of cigarette smoking was considered positive if the patient was an active smoker who smoked at least five cigarettes per day. Atrial fibrillation (AF) was evaluated on an ECG, carotid stenosis on carotid doppler ultrasound, and left ventricular (LV) dysfunction on an echocardiogram. Data entry and analysis were performed on Statistical Package for the Social Sciences (SPSS) version 20. Means, frequencies and percentages were calculated.

\section{RESULTS}

The study consisted of a total of 92 ischemic stroke patients among which 47 were male (51.1\%) and 45 were female (48.9\%). The mean age of the stroke patients was 63.25 years. The patients were grouped into the following age groups: $<45$ years, $45-69$ years, and $\geq 70$ years. Only $10(10.9 \%)$ patients were less than 45 years of age and 32 patients (34.8\%) were more than 70 years. The majority of patients that is 50 patients (54.3\%) were between 45-69 years of age (Table 1).

Among ninety two stroke patients studied, dyslipidemia $(77.2 \%)$ was found to be the most common risk factor, followed by smoking $(59.8 \%)$, presence of carotid artery atherosclerosis (59.8\%), hypertension (50\%), atrial fibrillation (AF) (26.1\%) and diabetes mellitus (DM) (15.2\%). Presence of family history of DM (4.5\%) and history of Rheumatic heart disease (RHD) (4.3\%) were the two least prevalent risk factors among the studied population (Table 3). 
Smoking was a significant association with the male group and dyslipidemia was mostly seen in female. Hypertension, atrial fibrillation, DM, family history of HTN and CVA was seen in equal proportion in both the sex. Hypertension, diabetes, dyslipidemia and AF were significantly associated with the occurrence of stroke in elderly (>70 years) and similarly dyslipidemia and hypertension were seen more in younger people (<45years) (Table 4).

ECG was done for the entire patient and there was morbidity on ECG in $46 \%$ of these patients. Atrial fibrillations were the most common cardiac abnormality detected in ECG and were present in 24\% of the patients. Other cardiac abnormality in ECG was left ventricular hypertrophy (LVH).

The ECHO study of the patients showed 10 (10\%) had left ventricular systolic dysfunction, 48 (52.2\%) had diastolic dysfunction and 35 (38\%) of the stroke patients had valvular heart disease. Similarly, patient's findings of Carotid Doppler is shown in Table 6.

Table 1: Distribution of patients according to age group and sex

\begin{tabular}{cccc}
$\begin{array}{c}\text { Age group } \\
\text { (years) }\end{array}$ & $\begin{array}{c}\text { Male } \\
\text { Number (\%) }\end{array}$ & $\begin{array}{c}\text { Sex } \\
\text { Number (\%) }\end{array}$ & Total \\
$<45$ & $8(80.0 \%)$ & $2(20.0 \%)$ & 10 \\
$45-69$ & $25(50.0 \%)$ & $25(50.0 \%)$ & 50 \\
$\geq 70$ & $12(37.5 \%)$ & $20(62.5 \%)$ & 32 \\
\hline
\end{tabular}

Table 2: Infarction location in the patients

\begin{tabular}{lc} 
Location of infarct & Number (\%) \\
\hline Anterior circulation & $69(75 \%)$ \\
\hline Posterior circulation & $8(8.7 \%)$ \\
Both territory & $15(16.3 \%)$ \\
b. Lacunar infarct & $26(28.3 \%)$ \\
\hline
\end{tabular}

Table 3: Distribution of various risk factors

\begin{tabular}{lc}
\hline Risk factors & Number (\%) \\
\hline Dyslipidemia & $71(77.2)$ \\
(Cholesterol> 200 or LDL $>100$ or $\mathrm{HDL}<40 \mathrm{mg} / \mathrm{dL})$ & $55(59.8)$ \\
Smoking & $55(59.8)$ \\
\hline Presence of carotid atherosclerosis & $52(56.5)$ \\
\hline High density lipoprotein (HDL)<40 mg/dL & $46(50)$ \\
\hline Hypertension (HTN) & $39(42.4)$ \\
\hline Low density lipoprotein (LDL)>100 mg/dL & $25(27.2)$ \\
\hline Total cholesterol >200 mg/dL & $24(26.1)$ \\
\hline Atrial Fibrillation (AF) & $14(15.2)$ \\
\hline Diabetes Mellitus (DM) & $12(13)$ \\
\hline Use of tobacco & $11(12)$ \\
\hline Heart disease & $10(10.9)$ \\
\hline Family history of hypertension & $8(8.7)$ \\
\hline History of stroke & $7(7.6)$ \\
\hline Family history of Cerebrovascular Accident (CVA) & $4(4.5)$ \\
\hline History of Rheumatic Heart Disease (RHD) & $5(5.4)$ \\
\hline History of Transient ischemic attack (TIA) & $4(4.3)$ \\
\hline Family history of DM & \\
\hline
\end{tabular}


Table 4: Distribution of risk factors among male and female stroke patients

\begin{tabular}{|c|c|c|}
\hline Variables & Males n (\%) & Females n (\%) \\
\hline Hypertension & $23(48.9)$ & $23(51.2)$ \\
\hline Diabetes Mellitus & $8(17)$ & $6(13.3)$ \\
\hline History of CVA & $4(8.5)$ & $4(8.9)$ \\
\hline History of RHD & $1(2.1)$ & $3(6.7)$ \\
\hline Family history of HTN & $5(10.6)$ & $5(11.1)$ \\
\hline Family history of DM & $1(2.1)$ & $3(6.7)$ \\
\hline Family history of CVA & $3(6.4)$ & $4(8.9)$ \\
\hline Smoking & $35(74.5)$ & $20(44.4)$ \\
\hline Vegetarian & $3(6.4)$ & $4(8.9)$ \\
\hline Mixed diet & $44(93.6)$ & $41(91.1)$ \\
\hline Alcohol & $26(55.3)$ & $18(40)$ \\
\hline AF & $12(25.5)$ & $12(26.7)$ \\
\hline Heart disease & $3(6.4)$ & $8(17.8)$ \\
\hline Dyslipidemia & $33(70.2)$ & $38(84.4)$ \\
\hline Cholesterol >200 mg/dl & $9(19.1)$ & $16(35.6)$ \\
\hline $\mathrm{LDL}>100 \mathrm{mg} / \mathrm{dl}$ & $17(36.2)$ & $22(48.9)$ \\
\hline $\mathrm{HDL}<40 \mathrm{mg} / \mathrm{dl}$ & $23(48.9)$ & $29(64.4)$ \\
\hline AF in ECG & $12(25.5)$ & $12(26.7)$ \\
\hline Carotid stenosis $>=70$ & $7(14.9)$ & $7(15.6)$ \\
\hline ECHO systolic dysfunction & $6(12.8)$ & $4(8.9)$ \\
\hline
\end{tabular}

Table 5: Distribution of risk factors among elderly and younger age groups

\begin{tabular}{|c|c|c|c|c|c|}
\hline \multirow{2}{*}{ Risk factor } & & \multicolumn{2}{|c|}{ Age in years } & \multicolumn{2}{|c|}{$\begin{array}{l}\text { Age in years } \\
\text { Number (\%) }\end{array}$} \\
\hline & & $<70$ n (\%) & $>70 \mathrm{n}(\%)$ & $<45 \mathrm{n}(\%)$ & $>45 \mathrm{n}(\%)$ \\
\hline \multirow{2}{*}{ Sex } & Male & $28(45.2 \%)$ & 19(63.3\%) & $3(25 \%)$ & $44(55 \%)$ \\
\hline & Female & $34(54.8 \%)$ & $11(36.7 \%)$ & $9(75 \%)$ & $36(45 \%)$ \\
\hline \multirow{2}{*}{ Hypertension } & Yes & $25(40.3 \%)$ & $21(70 \%)$ & $3(25 \%)$ & $43(53.8 \%)$ \\
\hline & No & $37(59.7 \%)$ & $9(30 \%)$ & $9(75 \%)$ & $37(46.2 \%)$ \\
\hline \multirow{2}{*}{ Diabetes } & Yes & $4(6.5 \%)$ & 10(33.3\%) & $1(8.3 \%)$ & $13(16.2 \%)$ \\
\hline & No & $58(93.5 \%)$ & $20(66.7 \%)$ & $11(91.7 \%)$ & $67(83.8 \%)$ \\
\hline \multirow{2}{*}{ Smoking } & Yes & $25(40.3 \%)$ & $21(70 \%)$ & $6(50 \%)$ & $49(61.2 \%)$ \\
\hline & No & $28(45.2 \%)$ & $9(30 \%)$ & $6(50 \%)$ & $31(38.8 \%)$ \\
\hline \multirow{3}{*}{ Alcohol } & Yes & $33(53.2 \%)$ & $11(36.7 \%)$ & $5(41.7 \%)$ & $39(48.8 \%)$ \\
\hline & No & $27(43.5 \%)$ & 19(63.3\%) & $6(50 \%)$ & $40(50 \%)$ \\
\hline & Occasionally & $2(3.2 \%)$ & $0(0 \%)$ & $1(8.3 \%)$ & $1(1.2 \%)$ \\
\hline \multirow{2}{*}{ Tobacco chewing } & Yes & $6(9.7 \%)$ & $6(20 \%)$ & $2(16.7 \%)$ & $10(12.5 \%)$ \\
\hline & No & $56(90.3 \%)$ & $24(80 \%)$ & $10(83.3 \%)$ & $70(87.5 \%)$ \\
\hline \multirow{2}{*}{ Atrial fibrillation } & Yes & $12(19.4 \%)$ & $12(40 \%)$ & $1(8.3 \%)$ & $23(28.8 \%)$ \\
\hline & No & $50(80 \%)$ & $18(60 \%)$ & $11(91.7 \%)$ & $57(71.2 \%)$ \\
\hline \multirow{2}{*}{ Heart disease } & Yes & $8(12.9 \%)$ & $3(10 \%)$ & $3(25 \%)$ & $8(10 \%)$ \\
\hline & No & $54(87.1 \%)$ & $27(90 \%)$ & $9(75 \%)$ & $72(90 \%)$ \\
\hline \multirow{2}{*}{ Dyslipidemia } & Yes & $52(83.9 \%)$ & 19(63.3\%) & $12(100 \%)$ & $59(73.8 \%)$ \\
\hline & No & $10(16.1 \%)$ & $11(36.7 \%)$ & $0(0 \%)$ & $21(26.2 \%)$ \\
\hline \multirow{3}{*}{ Atherosclerosis } & Yes & $35(56.5 \%)$ & $20(66.7 \%)$ & $6(50 \%)$ & 49(61.2\%) \\
\hline & No & $14(22.6 \%)$ & $6(20 \%)$ & $2(16.7 \%)$ & $18(22.5 \%)$ \\
\hline & Not Done & $13(21 \%)$ & $4(13.3 \%)$ & $4(33.3 \%)$ & $13(16.2 \%)$ \\
\hline
\end{tabular}


Table 6: Distribution of finding in Carotid Doppler study of patients

\begin{tabular}{ccc}
\hline Percentage of carotid artery stenosis & Cases (\%) \\
\hline 50 & $17(18.5)$ \\
$>50$ & $12(13)$ \\
\hline Not done & $14(15.2)$ \\
Normal & $19(20.7)$ \\
\hline
\end{tabular}

\section{DISCUSSION}

Age is one of the non-modifiable risk factor of stroke. Mean age of the stroke patients which was around 63 was consistent with the findings from a similar stroke registry in Nepal $(61)^{8,9}$, India $(63)^{11}$, China $(60)^{12}$, Bangladesh $(60)^{13}$. However, in contrast to the western countries (69 years in USA and 71 years in Italy), the mean age of the stroke onset was higher ${ }^{14}$. This may be due to inadequate monitoring of the health service and control of the common modifiable risk factors in developing countries like Nepal, Bangladesh, and India where the poverty line of the population is still on the higher side. In our study we found that dyslipidemia, smoking, carotid artery atherosclerosis, hypertension, atrial fibrillations, diabetes were the most common risk factors which were consistent with the previous study ${ }^{9,12}$.

Stroke registries from other regional countries, namely India and Taiwan, also showed a similar prevalence of vascular risk factors, with hypertension, smoking, dyslipidemia, and diabetes being the main culprits ${ }^{15,16}$.

It is also shown from our study that hypertension, diabetes, AF, dyslipidemia were mostly seen in the elderly age group of more than 70 years, whereas dyslipidemia and hypertension were commonly observed in young age groups of age less than 45 years. This was consistent with the study done in Bangladesh where risk factors comparison was done with similar age groups ${ }^{13}$.

When the risk factors of stroke were compared between the genders, smoking showed male predominance. This study was also in coherence with the other study where smoking was significantly associated as risk factors in male gender ${ }^{12,13}$

Imaging study was done in all the candidates, however due to financial and socioeconomic issues not all the

\section{REFERENCES}

1. World Health Organization. The World Health Report: Shaping the future. 2003. [FullText] patients could undergo the doppler study. Among 73 patients out of a total of 92 who underwent the imaging study, carotid stenosis more than $70 \%$ was seen in $14(15.29 \%)$ of the cases which was higher than the study done in Pakistan, but however the percentages are as high as $39 \%$ or higher mentioned in some local journals ${ }^{17}$. A recent study of 672 stroke patients showed evidence of high-grade stenosis (70\%-99\%) in 12\% patients ${ }^{18 .}$

Similarly studies have shown anterior circulation infarct to be the most common followed by lacunar infract which was similar to the study done in Indo-American stroke patients in New Jersey America ${ }^{11,13}$. However a few other studies from India and Pakistan also showed that lacunar strokes are the predominant stroke subtype ${ }^{19,}$ $20,21,22$.

Atrial fibrillation was the most common ECG abnormality followed by left ventricular hypertrophy (LVH) which was not similar to the study done in the past which showed ischemic heart disease was common followed by $\mathrm{LVH}$ and $\mathrm{AF}^{13}$. Similarly another study showed $\mathrm{LVH}$ to be the commonest, followed by ischemia and AF, which was also not consistent with our study ${ }^{12}$.

The ECHO finding in our study showed LV diastolic dysfunction to be the commonest abnormality which was also reported to be the commonest abnormality and also consistent with the study done in past ${ }^{12}$.

\section{CONCLUSION}

Dyslipidemia and smoking were the most common risk factors followed by carotid artery atherosclerosis. Patients with hypertension and dyslipidemia had higher incidence of stroke in both young and elderly group. Smoking habit was primarily seen among the male group and dyslipidemia was mostly seen in female.

2. Kannel WB, WolfPA. Epidemiology of cerebrovascular disease, vascular disease of Central Nervous System. Edinburgh: Churchill Livingstone; 1983.1-24. [FullText] 
3. Zoghbi W, Duncan T, Antman E, Barbosa M, Champagne B,Chen Detal.Sustainable Development Goals and the Future of Cardiovascular Health: A Statement From the Global Cardiovascular Disease Taskforce. Journal of the American Heart Association [Internet]. 2014 Sep [cited 2017 Nov17];3(5). [DOI]

4. Kim A, Johnston S. Global Variation in the Relative Burden of Stroke and Ischemic Heart Disease. Circulation [Internet]. 2011 Jul [cited 2017 Oct 13];124(3):314-23.[FullText| DOI]

5. Krishnamurthi R, Moran A, Forouzanfar M, Bennett D, Mensah G, Lawes C et al. The Global Burden of Hemorrhagic Stroke: a summary of findings from the GBD 2010 study. Global Heart [Internet]. 2014 Mar [cited 2017 Nov 3];9(1):101-6. [PubMed]

6. Vaidya A, Shakya S, Krettek A. Obesity Prevalence in Nepal: Public Health Challenges in a Low-Income Nation during an Alarming Worldwide Trend. Int J Environ Res Public Health [Internet]. 2010 Jun [cited 2017 Oct 6]; 7(6): 2726-44. [Full Text | DOI]

7. Ageing [Internet]. Economic and Social Development Unit, United Nations; 2017[cited 2019 Jun 14]. Available from: https://www.un.org/en/sections/ issues-depth/ageing/

8. Pathak V, Kanth R, Pant H. Stroke: a case series study in Nepal Medical College Teaching Hospital. Nepal Med Coll J [Internet]. 2006 Sep [cited 2017 Dec 4];8(3):180-1. [PubMed]

9. Devkota KC, Thapamagar SB, Malla S. Retrospective analysis of stroke and its risk factors at Nepal Medical College Teaching Hospital. Nepal Med Coll J [Internet]. 2006 Dec [cited 2017 Nov 2];8(4):269-75. [PubMed]

10. Naik M, Rauniyar RK, Sharma UK, Dwivedi S, Karki DB, Samuel JR. Clinico-radiological profile of stroke in eastern Nepal: a computed tomographic study. Kathmandu Univ Med J [Internet]. 2006 Apr-Jun[cited 2017 Nov 23]; 4(2):161-6. [Full Text | PubMed]

11. Biswas M, Sen S, Simmons J. Etiology and risk factors of ischemic stroke in Indian-American patients from a hospital-based registry in New Jersey, USA. Neurology Asia [Internet]. 2009 [cited 2018 May 11]; 14(2):81-6. [Full Text]

12. Khealani B, Khan M, Tariq M, Malik A, Siddiqi A, Awan $S$ et al. Ischemic Strokes in Pakistan: Observations from the National Acute Ischemic Stroke Database. Journal of Stroke and Cerebrovascular Diseases
[Internet]. 2014 Apr [cited 2018 May 11];23(6):1640-

7. [PubMed]

13. Bhowmik N, Abbas A, Saifuddin M, Islam M, Habib $R$, Rahman $A$ et al. Ischemic Strokes: Observations from a Hospital Based Stroke Registry in Bangladesh. Stroke Research and Treatment [Internet]. 2016 Sep [cited 2018 May 12]; 2016:1-13. [Full Text]

14. Wasay M, Khatri IA, Kaul S. Stroke in South Asian countries. Nat Rev Neurol [Internet]. 2014 Mar [cited 2018 May 15];10(3):135-43. [PubMed]

15. Sridharan SE, Unnikrishnan JP, Sukumaran S, et al. Incidence, types, risk factors, and outcome of stroke in a developing country the Trivandrum stroke registry. Stroke[Internet]. 2009 Feb [cited 2018 May 20];40(4):1212-8. [Full Text | PubMed | DOI]

16. Hsieh F-I, Lien L-M, Chen S-T, et al. Get With The Guidelines-Stroke performance indicators: surveillance of stroke care in the Taiwan Stroke Registry. Circulation [Internet]. 2010 [cited 2018 May 24];122(11):1116-23. [DOI]

17. Shaikh NA, Bhatty $S$, Irfan $M$, et al. Frequency, characteristics and risk factors of carotid artery stenosis in ischaemic stroke patients at Civil Hospital Karachi. J Pak Med Assoc [Internet]. 2010 Jan [cited 2018 May 27];60(1):8-12.[Full Text | PubMed]

18. Wasay M, Azeemuddin M, Masroor I, et al. Frequency and outcome of carotid atheromatous disease in patients with stroke in Pakistan. Stroke [Internet]. 2009 Mar [cited 2018 May 30]; 40(3):708-12. [Full Text | PubMed | DOI]

19. Aquil N, Begum I, Ahmed A, et al. Risk factors in various subtypes of ischemic stroke according to TOAST criteria. J Coll Physicians Surg Pak [Internet]. 2011 May [cited 2018 June 1]; 21(5):280-3. [Full Text| PubMed]

20. Razzaq AA, Khan BA, Baig SM. Ischemic stroke in young adults of South Asia. J Pak Med Assoc [Internet]. 2002 Sep [cited 2018 June 3]; 52(9):417-22. [Full Text | PubMed]

21. Deleu D, Hamad AA, Kamram S, et al. Ethnic variations in risk factor profile, pattern and recurrence of noncardioembolic ischemic stroke. Arch Med Res [Internet]. 2006 Jul [cited 2018 June 7]; 37(5):655-62. [Full Text| PubMed]

22. Sher K, Shah S, Kumar S. Etiologic patterns of ischaemic stroke in young adults. J Coll Physicians Surg Pak [Internet]. 2013 Jul [cited 2018 June 9]; 23(7):472-5. [Full Text| PubMed] 